Quality assurance and learning technologies: intersecting agendas in UK higher education

Su White

\section{The author}

Su White is the Learning Technology Co-ordinator within the Centre for Learning and Teaching at the University of Southampton. E-mail: saw@ecs.soton.ac.uk

\section{Keywords}

Higher education, Quality assurance, United Kingdom, New technology, Globalization, Learning

\section{Abstract}

This paper looks at developments in the use of learning technologies in UK higher education, particularly in recent years. It examines the agenda items for learning and teaching associated with the use of new technologies that have emerged in the context of the current agenda for quality assessment and assurance. The paper considers the ways in which the two agendas work in a complementary manner, and the ways in which they create tensions. Finally, it considers the likely path of future developments and considers a way forward in which existing tensions may be reconciled.

\section{Electronic access}

The current issue and full text archive of this journal is available at

http://www.emerald-library.com
Quality Assurance in Education

Volume $8 \cdot$ Number $1 \cdot 2000 \cdot$ pp. 7-15

(C) MCB University Press · ISSN 0968-4883

\section{Technology and the learning and} teaching agenda

\section{The emerging agenda}

It has been more than six years since the UK higher education (HE) community accelerated its progress towards technologyenabled learning and teaching through the nationwide initiative of the Teaching and Learning Technology Programme (TLTP). Over that period there has been a significant fall in the costs of computers coupled with an increase in the power that they can provide at the desktop. At the same time, individual institutions have invested in their campus networks, while across the UK academic community the extent and capacity of JANET and SuperJANET has increased (JANET, 1999). In addition, the Joint Information Systems Committee (JISC) has set in train a wide variety of initiatives and services to enrich the infrastructure of information nodes and gateways (JISC, 1999; NISS, 1999).

\section{Fostering development}

In a nationwide context, there have been a large number of technology-related projects, as well as the ongoing TLTP initiatives which have now funded more that 100 projects (NCT, 1999). Within England and Northern Ireland there has been the Fund for the Development of Teaching and Learning (FDTL) (HEFCE, 1996, 1998) and two JISC programmes, the Technology Application Programme (JTAP) and the Electronic Libraries (e-Lib) programmes. These have funded work on leading-edge technology applications in HE, some of which have been concerned with systematic approaches to the use of learning technologies. The Scottish funding council has also put some effort into this area, which might be seen to complement a national agenda to create a knowledge society. Notably among these initiatives is the Learning Technology Dissemination Initiative (LTDI) and the Metropolitan Area Networks (MAN) Initiative (SHEFC, 1999). UK universities have also participated in a range of HEoriented projects in technology in learning and teaching which have formed a component of the EU third and fourth Framework programmes and will be incorporated in the fifth Framework (CORDIS, 1999). BT have also supported some innovations through their development fund, as well as funding 
individual research fellows in $\mathrm{HE}$, some of whom are in the area of technological innovations for learning and teaching (BT, 1999).

One other technology-related growth area during this period has been evidenced by a small flourish in variously named learning resource/learning technology centres. These changes were predominantly, although not quite exclusively, in those institutions whose libraries were seen to need enhancing following the removal of the binary divide which aimed to some extent to put universities and the former polytechnics on a more equal footing.

\section{The research community}

While much of the work described above has been concerned with the development, implementation and dissemination of new practices for learning and teaching with technology, this area has also benefited from some growth in research. These include centres such as the Knowledge Media Institute and the Institute for Educational Technology at the Open University, and the University of Bristol's Institute for Learning and Research Technologies (ILRT), as well as variously named institutes for computerbased learning focus on learning technologies. Further research into the technology futures in $\mathrm{HE}$ can be found among some of the projects in the Economic and Social Research Council (ESRC) in their general programme under technology and people; innovation; knowledge; communication and learning. The ESRC also has relevant programmes such as the "Learning Society" and the "Virtual Society". Similarly, research looking at areas which impact on learning and teaching innovations can be found within Engineering and Physical Science Research Council funding themes such as human factors; human computer interaction; cognitive science and multimedia systems.

Alongside this proliferation in research and implementation projects the publications on learning and teaching and technology have increased and a large learning and teaching technology community has emerged. The community is evidenced not only by their publications across a wide range of journals, but also through large numbers of workshops, seminars and dissemination events and a large number of electronic discussion groups.

\section{Institutional developments}

Thus the UK academic community has seen a concerted effort to establish a high-quality sector-wide technological infrastructure, which although originally established to support research, has also grown and been developed to serve the needs of learning and teaching. The community of practitioners who craft the new technology-based learning experience has grown, and thus the learning and teaching technology community has also grown from the bottom up. However, in the middle of these two, at the level of the individual institution, activities are less welldefined. Some institutions have capitalised on the benefits of network investment and the climate of innovation brought about with the increased interest in the use of learning technologies. The literature would suggest that many institutions are engaged in smallscale experimentation in the use of learning technologies. However, as yet, given that there are some 130 universities and colleges of higher education, it is difficult to identify very many systematic approaches to large-scale institutional change through technology[1].

There has been some effort by the sector to assist in the development at an institutional level. To some extent the use of technology for learning and teaching comes within the remit of institutions' information system strategies. The JISC have run developmental projects in this area, have produced guidelines for the development of such strategies and provide ongoing support through their JISC ASSIST Centre. The TLTP established a Teaching and Learning Technology Support Network that built on the activities of the TLTP institutional projects funded under phase 1 and 2 of the TLTP funding. The TLTSN had a remit of supporting strategic and infrastructure change brought about by the use of new technology. This initiative, along with the CTIs, was superseded by the wider ranging Learning and Teaching Support Network, and 24 new subject centres which were in place at the end of 1999. These activities are to be managed from the Institute for Learning and Teaching.

\section{Drive for learning and teaching strategies}

Meanwhile, another drive has recently emerged which may take the development and application of learning technologies into a more integrated focus. This comes in the 
form of a new initiative to develop institutional learning and teaching strategies run by the Higher Education Funding Council for England (HEFCE), which in July 1999, announced the creation of a Teaching Quality Enhancement Fund.

This fund was established following a confidential report commissioned by HEFCE which summarised the status and content of existing learning and teaching strategies of the vast majority of those 130-plus universities, colleges and institutions of Higher Education Strategies who responded to a commissioned research survey (Gibbs, 1999).

In June 1999, the HEFCE invited all institutions to submit an Institutional Learning and Teaching Strategy (LTS) by January 2000. They have allocated $£ 52.5 \mathrm{~m}$ over three years to support institutions in implementing their strategies. The research, conducted by Gibbs, indicated that given the state of current practice, this was a viable initiative, but that many institutions might welcome guidance on developing and implementing a learning and teaching strategy.

This initiative will provide the framework which will enable institutions to identify, articulate and locate their strategies with respect to learning technologies, and place them in the context of their broader institutional mission and learning and teaching objectives.

Case study material illustrating best practice in a variety of institutions was collated by visiting institutions and reviewing documentation (HEFCE, 1999a). This material, along with the set of defined strategies, will perhaps help provide some clearer indication of current trends in strategic thinking across the sector.

The funding council's guidance document clearly indicates that it envisages the use of learning technologies as an integral part of institutional learning and teaching strategies. It states that the institutional strand of the funding could be directed at a number of areas including "innovations in learning and teaching, especially in the use of communications and information technology" (HEFCE, 1999b).

Among the six national priorities which institutions may wish to address in the content and structure of their strategies, the report suggests "transferring and adopting good practices in learning and teaching; for example, through collaboration between departments and between institutions. This may be on a regional basis, and may include, in particular, sharing good practice and developments emerging from the FDTL, TLTP and LTSN programmes". They might also consider "exploitation of communications and information technology in the service of managed improvements in learning and teaching".

\section{Additional influences}

\section{Government intentions}

Of course, the agenda for learning and teaching has not been immune from influences outside academia. Aside from the national inquiry into the future of $\mathrm{HE}$ (Dearing, 1997), government played a direct role commissioning reports designed to stimulate debate and initiate change in the possible future directions for $\mathrm{HE}$, and lifelong learning (Fryer, 1997; Kennedy, 1997). They have turned policy into practice by such actions as initiating the University for Industry (UfI, 1999) and working through the now combined Department for Employment and Education to fund subject discipline networks and the development of skills for university graduates which will enhance their employability.

Even inside universities, the driver for change has not been confined to the technological front. There has been a diminution of per capita funding, an increase in participation rates from 10 percent to 30 percent and more heterogeneous student groups. In addition, there have been government pressures to widen participation and enable lifelong learning. All these changes can be seen in different ways to have been associated with the upheavals that have followed on from the removal of the binary divide.

\section{Approaches to learning}

The development of approaches to learning has also taken place over time, and has experienced some interplay with the emerging learning and teaching agenda. A brief account of the history can help in understanding the nature of that agenda. The application of technology for use in learning and teaching is not new (Geoghegan, 1994), but early uses of educational technology were shaped by the 
nature of computer architecture, and prevailing beliefs about learning. This also shaped the learning technology agenda, where the early model that developed was predominantly one of delivering learning. Researchers were experimenting in this area along behaviourist models using early mainframes during the 1960s. The advent of first mini-, and then micro-computers brought about structural changes that enabled the adoption of new models of computer usage in the educational context. Carnegie Melon University engaged in campus-wide experimentation during the early 1980 s (Kiesler and Sproull, 1987). In the UK, encouragement for widespread usage of educational technology can be dated back to the establishment of the Computers in Teaching Initiative (CTI), also begun in the early 1980s. This was followed on by the TLTP which in the initial phases placed a big emphasis on the production of learning resources to be used in undergraduate teaching. The vast majority of the TLTP projects were concerned with the solution of particular learning and teaching problems within a specific course or curriculum area. Thus, in the UK, even in the early 1990s the predominant model was one of delivering learning via the computer. In addition, although there was a small number of institutional TLTP projects which addressed the issues of campus-wide implementation of learning technologies, the main part of the focus of the CTI and TLTP initiatives were top-down and sector-wide, rather than focussing on developments at individual institutions.

However, the transition from mainframe to micro-computers saw an emergence of constructivist views of education which were placed in the context of education technology during the early 1990s (Laurillard, 1993); (Jonasson and Mayes, 1993). This change in views has been accompanied by greater emphasis on uses which exploit the potential of the technology to enable and enhance communicative and collaborative interactions. Subsequently, in the UK, work has been done to follow through the change in the theoretical framework (Bostock, 1998; Conole and Oliver, 1998). The theoretical change was also followed through by Dearing in the review of UK HE (Dearing, 1997), when he explicitly recast the focus of university education by putting the learning in front of the teaching. The report also reinforced the view of the future direction of technology-based learning applications by putting communications firmly in front of Information Technology (IT).

\section{The agenda emerges}

The aspect of the learning and teaching agenda which emerged from the changes in the thinking on pedagogical approaches within higher education can be identified by the current set of buzz words operating in the learning and teaching community. The vocabulary associated with learning technologies reflects the particular nature of experience in which the technologies exist. Thus it is most straight forward to identify the agenda for learning technologies through a cluster of closely-related, but not interchangeable words and phrases, which describe the areas of focus. We find the agenda for learning technologies in areas such as:

- independent and self-directed learning;

- flexible learning;

- open and distance learning;

- resource-based learning;

- computer-mediated communication;

- computer-supported collaborative work;

- computer-supported collaborative learning.

It is important to note that these perspectives do not exist solely within the context of technology in $\mathrm{HE}$, as many of these areas are synonymous with key areas of development for generic approaches to learning and teaching.

Additional issues which have arisen in the learning and teaching context (which are perhaps more specific to technology) include the use of computer-assisted assessment.

However, here, many of the issues addressed are those which belong in the general area of assessment. Other examples include the integration of the use of technology into the whole academic programme and the evaluation of the use of learning technologies.

It should be noted that, as with face-to-face methods, the particular mix, and emphasis in the use of different processes mediated by learning technologies will vary. It will differ from subject to subject according to the demands of the discipline and the resources available at the institution where the processes are taking place. Critical factors for success 
(besides the selection of appropriate uses of technology) will be such items as the staff skills, technical support and the technological infrastructure available to support the learning (Hall and White, 1997).

As has been noted, these are much the same as the set of key themes which belong to learning and teaching as a whole. This fact alone would argue for a transparent approach to the assessment of quality in learning and teaching. The acknowledged observation that if it is to be successful, technology has to be integrated into the teaching and learning process (Maier and White, 1997) only serves to reinforce this argument.

However, there is a second agenda area, which is raised by those using technology for learning and teaching. This is concerned predominantly with technical issues such as the technological infrastructure, capabilities of the platform, the availability of machines for student use, and production values of software. In addition, from a quality perspective there are other less tangible areas which we might wish to assess, such as the quality of the learning experience with computers.

\section{The quality agenda}

\section{How the agenda has emerged}

The parameters of change that have affected the quality agenda were described by Green (1994) as follows:

- $\quad$ rapid expansion of student numbers against a backcloth of public expenditure worries;

- the general quest for better public services;

- increasing competition within the educational "market" for resources and students;

- the tension between efficiency and quality.

It is possible to see that these factors have also had a significant presence in determining the direction of a large part of the focus of learning and teaching agenda in recent years. The reader will recognise them generally from the account which has already been made in this paper.

There would seem to be a particularly close relationship between the quality agenda described by Green and the stated remit of the first phase of the TLTP programme. This was established with the original stated purpose of increasing effectiveness and efficiency of the use of technology in learning and teaching. Many initial projects specifically dealt with issues on handling increasingly large student numbers.

There has been a growth in the belief that the use of technology will provide new ways of delivering and supporting learning and teaching, and discussions of the future of the virtual university abound (Brown, 1998; Newby, 1999). There is some debate as to whether the use of technology for learning and teaching actually delivers any financial savings (HEFCE, 1997). While some research has shown that the view of the learners is frequently that they do not wish technological solutions to replace face-to-face teaching (Light and Colbourn, 1997).

Institutions have increasingly competed via technological infrastructure resources. Studies of prospectuses bear out the observation that information technology is used as a selling point in the marketing of courses to students (Crook and Light, in press).

Four concepts of quality

Green also identified four concepts of quality in $\mathrm{HE}$ :

(1) The traditional concept of quality.

(2) Conformance to specifications or standards.

(3) Quality as effectiveness in achieving institutional goals.

(4) Quality as meeting customers' stated or implied needs.

It is useful to consider the extent to which these concepts are relevant or useful to quality of learning technologies. In many cases it appears that the learning technologies agenda sits less comfortably with this agenda. It is perhaps worth considering each point in a little greater detail.

\section{The traditional concept of quality}

Across the UK as a whole there has been a move to establish a "gold standard" network infrastructure through the provision of JANET and SuperJANET. However, as has been noted, individual institution's efforts to be leading players in the use of learning technologies are less clear cut. Some institutions have established themselves reputations as hosts of key data archives. Some institutions pride themselves on the 
quality of their campus network, others on their high levels of workstation provision, the availability of sparkling learning resource centres, or provision of network points from all study bedrooms. Measures of such infrastructure are not consistent, and the relative value of each different type of technological richness is not clearly defined.

Individual institutions have most recently been measured on a points system, which enables the creation of league tables, and thus a ranking against the standard, which can also be compared to more subjective perceptions of which institutions are the leaders in any particular subject. But the measures of learning technology are spread across the assessment criteria. Even if future reviews are not measured on this style of points system, an established order has by now been created against which future performances can be gauged.

\section{Conformance to specifications or standards}

Among the recommendations of the Dearing report (1997) was a proposal that an Institute for learning and teaching would be responsible for the kitemarking of computer software. There is not, as yet, a pre-specified level of provision either with respect to the content of teaching, or the ways in which technology is used to mediate the learning and teaching processes. Institutions frequently calculate and publicise the ratio of computers to students, the number of hours of access available, and information such as the range of software used. However, there is no absolute baseline to which all institutions conform, nor is it clear, if such a baseline existed, what purpose it would serve.

Furthermore, in some areas, such as the use of computer-mediated communication (CMC) to enable learning, it is difficult to see how there could be a measured standard or specification against which such an activity could be gauged. Given that CMC is the area which is probably experiencing the greatest growth in applications for learning and teaching, this suggests an ongoing tension in terms of the quality of performance of technology-enabled learning and teaching.

\section{Quality as effectiveness in achieving institutional goals}

As has been discussed, there is now considerable activity in moving institutions towards a position where they will be assessing the quality of the use of learning technology in terms of its effectiveness in achieving institutional goals.

For many institutions early use of technology in learning and teaching made use of the role which IT has to play in terms of building employability and key skills. This is one of the checklist points which HEFCE provide within their suggested framework for learning and teaching strategies; "Promoting innovation in the curriculum, particularly activity to increase the employability of graduates and diplomates including work experience and developing key skills". However, links between the learning and teaching technology agenda, and the quality agenda are likely to be more wide ranging and explicitly linked in future.

\section{Quality as meeting customers' stated or implied needs}

The concept of learner as customer is becoming more prevalent in HE. Perhaps this is a factor which has higher prevalence among part-time or distant learners, although the introduction of tuition fees is acknowledged as bringing forth a customer-style attitude from full-time undergraduates as well. This relates much more than any of the other factors to that part of the learning and teaching agenda which focuses on the learners' experience, and again chimes with the greater use of CMC for student tutorials and such like. The ability of computer software to enable learners to proceed in their own time, and at their own pace is well acknowledged, and the use of CMC for asynchronous discussion allows for a flexibility in terms of time. Both of these factors are resonant with government agendas for lifelong learning and widening participation. However, it is not clear if current quality assessments really measure this meeting of needs, or indeed how it would be possible to measure such effectiveness.

\section{Learning technologies in quality assessments}

Another way in which to consider the interaction between the quality agenda and the learning and teaching agenda is via the framework that has been established for subject assessments. There is a considerable amount of evidence of the actual relationship to be found in both individual and summary 
subject reports. The illustrative quotes used below have been taken from the summary report for electrical and electronic engineering (QAAHE, 1998), although similar statements are to be found in other reports from across the discipline range. Although to date the assessment of learning technologies with subject assessments has formally come under the heading of Learning Resources, further references can be found throughout the reports. For example, in the electrical and electronic engineering subject overview report summary section noted that: "Some providers deploy a wide range of teaching and learning methods, including computer-aided learning (CAL) and the use of the Internet. In the best examples, the use of directed and

independent learning is well integrated with taught elements... Learning resources fully support the provision in a majority of cases. Most of the computing and IT facilities are high quality".

Within the body of the report, the use of learning technologies is discussed under three sections. Under the section on teaching, learning and assessment it states:

The teaching and learning strategies typically involve a variety of activities including lectures, seminars, tutorials, individual and groups project work and directed learning. Providers achieving the highest grade generally deploy a wide range of teaching and learning methods, including CAL and the use of the Internet. In the best examples, the use of directed and independent learning is well integrated with taught elements.

It goes on and notes in the conclusions that: In most cases the assessors identified some scope for improvements in teaching and learning.

Under the section on student support and guidance it is noted that an increasing number of institutions provided information that could also be accessed electronically through the campus Web site, and that facilities for extra subject learning was sometimes included centrally, including the use of CAL. Under the learning resources section it noted that:

Most of the computing and IT facilities are of high quality, a wide range of networked hardware and software is available for use by students in most institutions. Computing facilities are accessible for up to 24 hours a day and in some cases student accommodation is networked.

The examples indicate the extent to which learning technologies already fall across the broad assessment areas. This is a de facto argument for the transparent assessment of such technologies.

\section{Learning technology futures}

As was shown at the beginning of this paper, the sector has been thorough in establishing a high quality technological infrastructure available for use in learning and teaching. Considerable effort has been put into developing information gateways and amassing national data archives which can be accessible throughout the sector. However, developments of actual uses of learning technology have been more ad hoc, although there have been a number of notable national and international initiatives supporting developments in this area. In addition, despite the flurry of activity which has been described in the area of technologically-enabled learning and teaching, there are some who argue that the level of sophistication with which we make use of educational technology has still not progressed past the Model T Ford days (Benyon and Stone, 1997).

The situation is bound to change given the ongoing growth on research into the use of technology for learning and teaching. Change will also be brought about by the activities of the growing numbers of both learning technologists and technologically-adept academics evidenced via the thriving learning technology community. The largest gap exists at an institutional level, although the impact of initiatives such as the Teaching Quality Enhancement Fund (TQEF), may mean that this period of ad hoc growth is drawing to a close.

In England and Northern Ireland at least, the ongoing development of learning and teaching strategies will bring about more clearly-articulated approaches to the use of learning technologies, and may well lead to "joined up" strategies. Such strategies would integrate the use of technology into general learning and teaching approaches in a way which is of benefit to learners and faculty alike. It is likely that the funding attached will be an incentive to such work, while the proposed structure of self-set targets, plus a desire to be seen to do well in such a public arena, will be a great benefit in actually making some change in this underdeveloped area. 
Institutional level changes may also be a consequence of a response across the sector to the strength of government intent to alter the nature of HE. This intent aims to harness $\mathrm{HE}$ to work with and for the needs of a nation, which exists and wishes to compete effectively within a global knowledge economy.

Assessing the use of learning technologies in a transparent manner will provide the necessary latitude to accommodate varying levels of technological infrastructure, and evaluate the effectiveness of technology in the context, which it actually exists.

As can be seen from the examples drawn from the quality assessment, the assessment system already implicitly recognises the dispersed nature of impact of learning technologies. Reference to technologies in so many different locations would seem to acknowledge that this is the proper way in which to assess the impact of such technologies. However, it remains that in the area of subject review, this acknowledgement is currently implicit, although there are perhaps changes in train. A recent publication from the Quality Agency (QAAHE, 1999) talks about the systems design of distance learning. This document argues for transparency via an integrated approach.

\section{Conclusion}

An examination of developments in the use of technology in learning and teaching shows the extent to which the drivers for change in the quality agenda have also operated in the learning and teaching arena. In many ways the values and methods which are applied to quality assessment can also be applied to the use of technology for learning and teaching. To date the ad hoc development of the use of technology for learning and teaching has not had strong institutional linkages. However, quality is becoming a driver for change in the institutional area via initiatives such as the TQEF. Initiatives like the TQEF match a growing recognition from some of HE's own managers of the extent to which technology for learning and teaching is an integral part of the future of UK and global HE.

In addition, it is important to recognise that in some ways the assessment and assurance of quality may act as an inhibitor to the growth and development of effective use of technology for learning and teaching. Fear of falling short of the highest standards may encourage the retention of old methods and discourage experimentation with new.

At the practitioner level, much work still needs to be done on the evaluation of the effectiveness of learning technologies, and it will take a period of extended usage to provide the experience. This perhaps presents an area of challenge for the quality assessment of teaching methods. It is important for the sector that care is taken to ensure that this important work is nurtured. Greater transparency in the quality assessment processes under subject review will encourage the integration of the use of technology into the whole range of processes associated with learning and teaching. In this way it may be possible, despite assessment pressures, for academics and learning technologists to find sufficient space for developmental and reflective uses of technology for learning and teaching. Such transparency, when coupled with external drivers for general quality enhancement such as the professionalisation of teaching in UK HE, will see the integration of new methods into our everyday practices.

\section{Note}

1 There are major projects at a number of universities; for example, the Open University's inclusion of technology in their distance learning; the campuswide adoption of Web-CT at Sheffield University, the Electronic Campus at De Montfort University, Learn Online at Coventry, the UNNFURL Initiative at the University of Northumbria in Newcastle, and the institution-wide use of Computer Assisted Assessment at the University of Luton. Other institutions of high activity include Oxford Brookes, University of the Highlands and Islands, Lincoln and Humberside, Loughborough, Napier, Glasgow and Strathclyde, Thames Valley University and Sheffield Hallam.

\section{References}

Benyon, D. and Stone, D. (1997), "Experience with developing multimedia courseware for the World Wide Web: the need for better tools and clear pedagogy", International Journal of HumanComputer Studies, Vol. 47, pp. 197-218.

Bostock, S.J. (1998), "Constructivism in mass higher education: a case study", British Journal of Educational Technology, Vol. 29 No. 3, pp. 225-40.

BT (1999), University Challenge, October, http:// innovate.bt.com/uni_links/index.htm

Brown, S. (1998), "Reinventing the university", ALT-J, Vol. 6 No. 3, pp. 30-7. 
Conole, G. and Oliver, M. (1998), "A pedagogical framework for embedding C\&IT into the curriculum", ALT-J, Vol. 6 No. 2, pp. 4-16.

CORDIS (1999), Community Research and Development Information Service, October, http://www.cordis.lu/

Crook, C.K. and Light, P. (in press), "Information technology and the culture of student learning", in Bliss, J., Light, P. and Saljo, R. (Eds), Learning Sites.

Dearing, R. (1997), Higher Education in the Learning Society, HMSO, London.

Fryer, R.H. (1997), Learning for the 21st Century, National Advisory Group for Continuing Education and Lifelong Learning.

Geoghegan, W.H. (1994), "Whatever happened to instructional technology?", 22nd Annual Conference of the International Business Schools Computing Association, IBM, Baltimore, Maryland.

Gibbs, G. (1999), Institutional Teaching and Learning Strategies: A Summary of Current Practice, Centre for Higher Education Practice, Open University.

Green, D. (1994), "What is quality in higher education?", Concepts, Policy and Practice, Open University Press, Buckingham, pp. 3-20.

Hall, W. and White, S. (1997), "Teaching and learning technology: shifting the culture", in Armstrong, S., London, T.G. and London, B.S. (Eds), Facing Up to Radical Change in Universities and Colleges, Kogan Page.

HEFCE (1996), Evaluation of the Teaching and Learning Technology Programme, Higher Education Funding Council for England (HEFCE), Bristol.

HEFCE (1997), Information Technology Assisted Teaching and Learning in UK Higher Education, Higher Education Funding Council for England (HEFCE), Bristol.

HEFCE (1998), Evaluation of the Fund for the Development of Teaching and Learning, HEFCE, Bristol.

HEFCE (1999a), Institutional Learning and Teaching Strategies, HEFCE, Bristol.

HEFCE (1999b), Teaching Quality Enhancement Fund: Funding Arrangements, HEFCE, Bristol.

JANET (1999), General Information about JANET and SuperJANET, http://www.ja.net/general/.
JISC (1999), The Joint Informations Systems Committee, October, http://www.jisc.ac.uk/

Jonasson, D. and Mayes, T. (1993), "A manifesto for a constructivist approach to uses of technology in higher education", in Duffy, T.M., Lowyck, J. and Jonassen, D.H. (Eds), Designing Environments for Constructivist Learning, Springer Verlag, Berlin, pp. 231-47.

Kennedy, H. (1997), Learning Works: Widening Participation in Further Education, Further Education Funding Council, Coventry.

Kiesler, S. and Sproull, L. (1987), Computing and Change on Campus, Cambridge University Press, Cambridge.

Laurillard, D. (1993), Rethinking University Teaching: a Framework for the Effective Use of Educational Technology, Routledge, London.

Light, P. and Colbourn, C. (1997), "Computer mediated tutorial support for conventional university courses", Journal of Computer Assisted Learning, Vol. 13 No. 4, pp. 228-35.

Maier, P. and White, S. (1997), "Using educational development strategies to integrate learning technologies within a HE institution", Active Learning, Vol. 6, July.

NCT (1999), National Co-ordination Team, October, http:// www.ncteam.ac.uk

Newby, H. (1999). "Higher education in the twenty-first century: some possible futures", University of Southampton, New Reporter, Vol. 16 No. 14.

NISS (1999), National Information Services and Systems, November, http://www.niss.ac.uk/subject/

QAAHE (1998), Quality Assessment of Electrical and Electronic Engineering, QAAHE, Cheltenham.

QAAHE (1999), Guidelines on the Quality Assurance of Distance Learning, QAAHE, Cheltenham.

SHEFC (1999), SHEFC Communications and Information Technology (C\&IT) Programme, October, http:// www.scotcit.ac.uk/

UFI (1999), The National Learning Network, Research Network for the University for Industry, October, http://national.learning.net.uk/ 